\title{
Influence of previous acid etching on interface morphology and bond strength of self-etching adhesive to cavosurface enamel
}

\author{
Adriano Fonseca Lima' \\ Vinícius Brito da Silva ${ }^{1}$ \\ Giulliana Panfiglio Soares ${ }^{1}$ \\ Giselle Maria Marchi ${ }^{1}$ \\ Flávio Henrique Baggio Aguiar ${ }^{1}$ \\ José Roberto Lovadino ${ }^{1}$
}

\begin{abstract}
Objectives: The aim of this study was to evaluate the (1) bond strength of a etch-and-rinse and self-etching adhesive systems to cavosurface enamel, (2) influence of the previous acid etching with phosphoric acid 35\% to the self-etching adhesive application on bond strength values, and (3) analysis of the cavosurface enamel morphology submitted to different types of conditioning, with the use of a scanning electronic microscope (SEM).

Methods: Twenty four human third molars were sectioned on mesio-distal direction, resulting in two slices. The specimens were ground flat with 600-grit aluminum oxide papers, and were randomly divided into three groups: Group 1 (etch-and-rinse adhesive system (control group)), Group 2 (selfetching adhesive), and Group 3 (self-etching adhesive with previous 35\% phosphoric acid-etching for $15 \mathrm{~s})$. Four cylinders ( $0.75 \mathrm{~mm}$ of diameter, $1 \mathrm{~mm}$ height) were confectioned prior to the microshear test. Four samples for each group were prepared according the cavosurface enamel treatment and were analyzed in an SEM.

Results: Group 3 had the highest values on bond strength to cavosurface enamel compared to the other two groups, which presented statistically similar values. The performance of acid etching before the application of the self-etching adhesive results in an etching pattern that is different than the other groups, favoring the adhesion to the cavosurface enamel.

Conclusions: Acid etching increases the bond strength values of the self-etching adhesive to cavosurface enamel, promoting a conditioning pattern that favors the adhesion to this substrate. (Eur J Dent 2012;6:56-62)
\end{abstract}

Key Words: Bond strength, enamel, self-etching adhesive, adhesive system, acid-etching

1 Department of Restorative Dentistry, Piracicaba School of Dentistry, State University of Campinas - Brazil

- Corresponding author: Dr. José Roberto Lovadino, Departamento de Odontologia Restauradora, Faculdade de Odontologia de Piracicaba - UNICAMP, Av: Limeira Areião. CEP: 13414-903, Piracicaba, SP, Brasil Phone: +55-19-2106-5340 Fax: +55-19-2106-5218. e-mail: lovadinolfop.unicamp.br

\section{INTRODUCTION}

Adhesive systems are important for the success of minimally invasive dentistry, given that superior performance in the maintenance and seal of the restorations is essential for the longevity of the restoration process. Two categories of adhesive systems are currently used in dentistry: total-etching 
or etch-and-rinse adhesives and self-etching adhesive systems. Etch-and-rinse adhesive systems require previous acid etching of the surface, which creates micro-retentions that permits the micromechanical interlocking of the adhesive system to the dental substrate. ${ }^{1}$ On the other hand, selfetching adhesive systems include a primer that performs the surface conditioning with concomitant monomer infiltration, promoting the formation of the hybrid layer. ${ }^{1}$

However, the effectiveness and longevity of the bonding to the dental substrate is influenced not only by the adhesive system used, but also by the moisture of the substrate ${ }^{2}$ and type of surface on which the adhesive procedure is executed..$^{3-5}$

Even with adequate bond strength to the den$\operatorname{tin}^{6-9}$ the results of self-etching systems on enamel are still inferior to those obtained through etchand-rinse adhesives. ${ }^{10,11}$ Numerous researchers have evaluated the bond strength of self-etching adhesives subsequent to the acid etching of the enamel surface and highlighted the inefficiency of this method in increasing bond strength values. ${ }^{12-14}$ However, most of the studies evaluate the vestibular and/or lingual enamel, not the adhesion of the self-etching systems to the cavosurface enamel, which is an important region in the seal and clinical success of Class I and II restorations.

Therefore, the objectives of the present study were: (1) to evaluate the bond strength of a etchand-rinse and a self-etching adhesive system to the cavosurface enamel; (2) to investigate the influence of acid etching prior to the application of the self-etching adhesive on bond strength values; (3) to examine the substrate's morphology after different etching protocols, with the use of a scanning electron microscope (SEM). The first null hypothesis of the present study was that all the adhesive systems would show similar bond strengths, regardless of the conditioning type of the cavosurface enamel. The second null hypothesis was that the morphological characteristics of the conditioned region would not differ.

\section{MATERIALS AND METHODS}

After obtaining approval to conduct the present study from the Commission for Ethics (\#105/2007), 24 freshly extracted human third molars were stored in thymol solution $0.1 \%$. The teeth were cleaned, and one section was done on mesio-distal direction, resulting in two halves. The specimens presented the cavosurface enamel exposition similar to that which is obtained in Class I restorations. This surface was ground flat with 600-grit aluminum oxide papers (Arotec Ind. Com. Ltd., Cotia, SP, Brazil) under constant water cooling to promote smear layer compatibility with the clinical situation. After the confection of the samples, they were randomly divided into three groups ( $n=12)$.

Group 1 (Control Group): Acid etching with 35\% phosphoric acid (Scotchbond, 3M ESPE, St. Paul, MN, EUAl for $15 \mathrm{~s}$. Then, the surfaces were washed with distilled water for $15 \mathrm{~s}$ and air dried. The etchand-rinse adhesive system was subsequently applied (Adper Single Bond 2 Plus, 3M ESPE, St. Paul, $M N, E U A l$ according to the manufacturer's instructions and light cured for $10 \mathrm{~s}$.

Group 2: Self-etching adhesive (Clearfil SE Bond, Kuraray Medical, Osaka, Japan) was used according the manufacturer's instructions. The samples were prepared through the following steps: application of the primer agent, airflow gently for $20 \mathrm{~s}$, bond application, airflow gently for $20 \mathrm{~s}$, and light cured for $10 \mathrm{~s}$.

Group 3: The samples were prepared through the following steps: acid etching with $35 \%$ phosphoric acid of the cavosurface enamel for $15 \mathrm{~s}$, washed with distilled water for $15 \mathrm{~s}$, and air dried. Then, the application of the self-etching adhesive (Clearfil SE Bond) was carried out using a similar procedure to group 2.

After the adhesive protocol respective to each group, four molds with a cylinder shape $10.75 \mathrm{~mm}$ diameter, $1 \mathrm{~mm}$ height) were positioned on the cavosurface enamel, filled with a flow composite resin (Opallis Flow; FGM, Joinvile, SC, Brazil), and light cured for $40 \mathrm{~s}$. This composite resin was used due to its lower viscosity, facilitating the insertion of the material on the molds.

For the polymerization process, was standardized a $1 \mathrm{~mm}$ distance between the tip of the light source and dentin. Both adhesive systems and the composite resin were light cured with a halogen lamp device (Optilux 501, Sybron Kerr, Danbury, CT, USA). The device's irradiance was constantly monitored and remained around $600 \mathrm{~mW} / \mathrm{cm}^{2}$. After the confection of the cylinders, the specimens were analyzed with a stereomicroscope ( $\times 20$ magnification, Meiji 200, Meiji Techno, Tokyo, Japan) to observe the integrity of the teeth-restoration interface. 
After 24 hours, the specimens were fixed to a micro-shear device adapted to a load testing machine (EMIC DL 500, EMIC Equipamentos e Sistemas de Ensaio Ltda, São José dos Pinhais, SC, Brazil.). A thin wire (0.3 $\mathrm{mm}$ thickness) was also looped around the interface between the tooth and resin composite. The shear force was then applied at a cross-head speed of $0.5 \mathrm{~mm} / \mathrm{minute}$ until debonding. The values were obtained in $\mathrm{KgF}$ and were converted in $\mathrm{MPa}$, which involved dividing the force $(\mathrm{KgF})$ by the adhesive interface $\left(\mathrm{cm}^{2}\right)$.

The normality of the data was evaluated by Shapiro-Wilk and Kolmogorov-Smirnov tests. In addition, a one-way analysis of variance (ANOVA) was performed to compare the experimental and control group. Finally, a Tukey post-hoc test was conducted for multiple pairwise comparisons (a=.05).

Morphological analysis of the cavosurface enamel on SEM

Four specimens for each group were observed in an SEM for the morphology analysis of the cavosurface enamel submitted to different surface treatments. The teeth were prepared in a similar way as in the adhesive procedure. The etching with $35 \%$ phosphoric acid of the enamel was performed by $15 \mathrm{~s}$. Then, the surface was washed for $15 \mathrm{~s}$ and air dried. In group 2, the primer was applied according to the manufacturer's instructions. It was removed after $20 \mathrm{~s}$ and washed with ethanol and acetone for $10 \mathrm{~s}$ in each solution, alternating the solutions for $1 \mathrm{~min}$. In group 3, the acid etching was performed for $15 \mathrm{~s}$ prior to the application of the primer. In addition, the surface was washed for 15 $s$ and air dried. Finally, the primer was applied and removed in the same way as in group 2 .

All specimens were submitted to dehydration in ascending concentrations of ethanol $130 \%, 50 \%$, $70 \%, 90 \%$, and $100 \%$ ). The samples were subsequently gold sputtered (Desk II, Denton Vacuun Inc., NJ, USA) and analyzed using an SEM (JSM - 5600 - JEOL USA, Inc., Peabody, MA, USA). The etching pattern was performed with a descriptive analysis related to the morphologic characteristics.
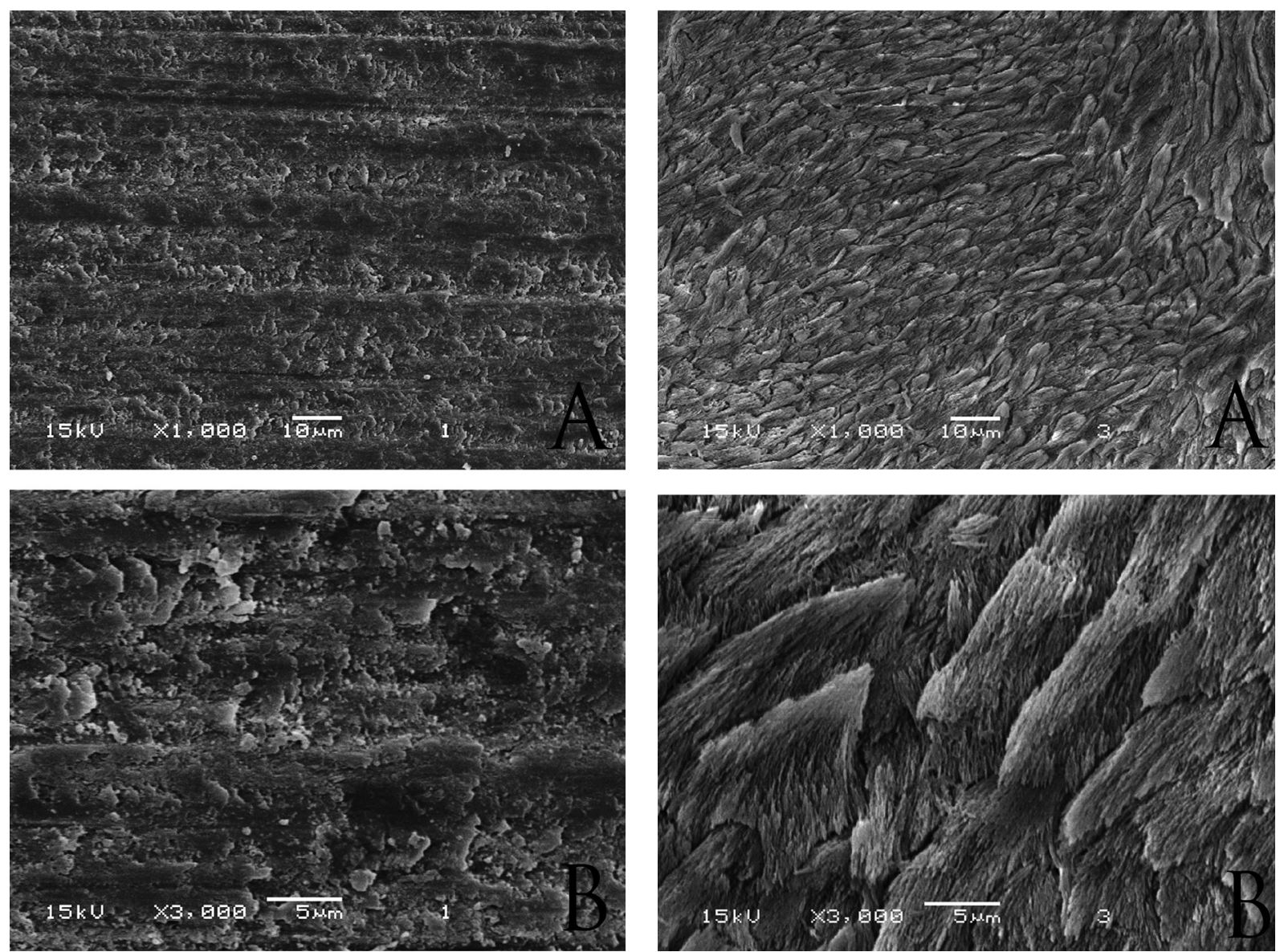

Figure 1. View of grounded cavosurface enamel without acid etching. $(A \times 1000 ; B$ $\times 3000$ ).

Figure 2. Cavosurface enamel after acid-etch with $35 \%$ phosphoric acid. Note the demineralization of the central region of the prisms $(A \times 1000 ; B \times 3000)$.

European Journal of Dentistry 


\section{RESULTS}

Microshear Bond Strength

The results collected regarding bond strength obtained through the microshear test are presented in Table 1. The group in which the self-etching adhesive method was used presented statistically similar results to the group in which the adhesive procedure using the etch-and-rinse adhesive system was performed. When the etching with 35\% phosphoric acid was carried out prior to the application of the self-etching adhesive system, the bond strength was significantly greater than the other groups.

Analysis of the morphology of the conditioned surface through SEM

When a cavosurface region without conditioning
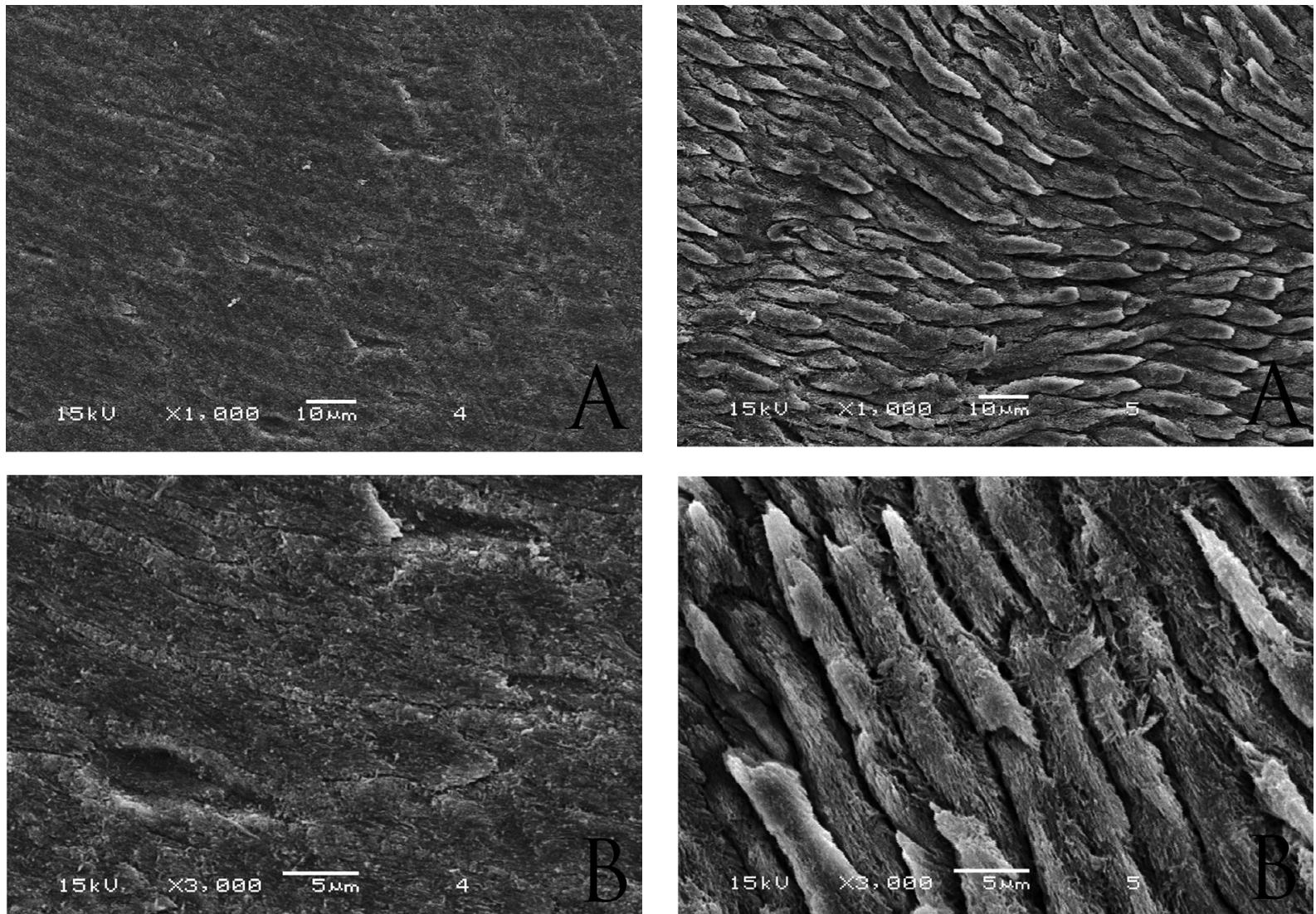

Figure 3. Cavosurface enamel etched only with the primer of the self-etching adhesive. Note the slight etching, with only remove of the smear layer, and discrete delimitation of the enamel prisms $(A \times 1000 ; B \times 3000)$

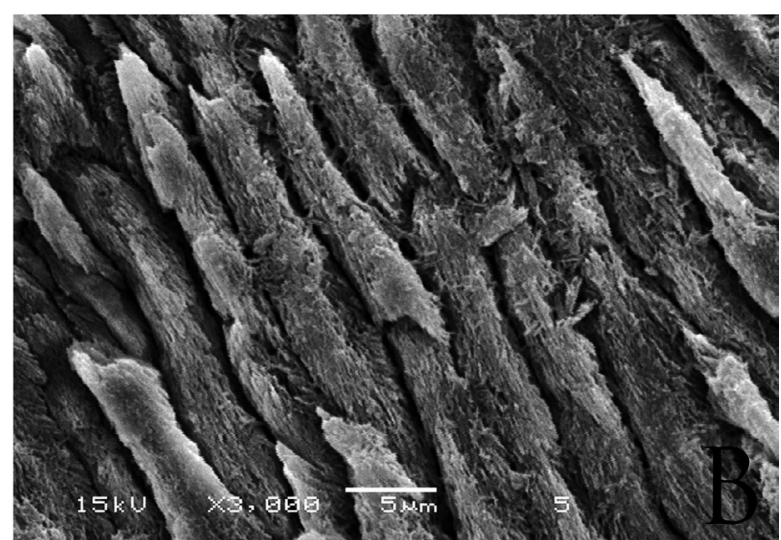

Figure 4. Enamel etched with the combination of the treatments: $15 \mathrm{~s}$ of phosphoric acid and $20 \mathrm{~s}$ of self-etching primer. Note the demineralization of both central and peripheral region of the prisms. $(A \times 1000 ; B \times 3000)$.

Table 1. Means (MPa) and standard deviations of experimental groups

\begin{tabular}{lll}
\hline Treatment & Means \pm SD & \\
\hline Single Bond 2 & $14,84 \pm 4,49$ & b \\
Clearfil SE Bond & $14,85 \pm 4,57$ & b \\
Etching with phosphoric acid 35\% + Clearfil SE & $18,63 \pm 4,93$ & a \\
\hline
\end{tabular}

Means followed by distinct letters are significantly different $(P=.026)$. 
etching of the surface, with exposure of not only the enamel crystals, but also their peripheral area (Figures $4 a$ and $4 b$ ).

\section{DISCUSSION}

Due to the group with the double etching (35\% phosphoric acid by $15 \mathrm{~s}$ and primer application) presents the better values on the bond strength, the first hypothesis of the present study was rejected.

Through the morphological analysis of the etched enamel, it was noted that the demineralization of the central region of the prisms (Figures $2 a$ and $2 b$ ) in the specimens etched with $35 \%$ phosphoric acid was more expressed than the one found when only the primer of the adhesive system Clearfil SE Bond was applied (Figures 3a and 3b). Regardless, the results for both groups were statistically similar, which is inconsistent with the findings of other researchers. ${ }^{12,14,15}$ This can be explained by the use of different methodologies as well as the region evaluated. In several studies, the bond strength was assessed in the vestibular and lingual region of the teeth, $12,13,16$ with a different orientation of the prisms, which could have influenced the retention of the various adhesive systems. In the vestibular regions, the enamel prisms are conditioned in a sagital way, which can influence the demineralization by the self-etching adhesive system primer and the monomer infiltration. ${ }^{17}$

Another factor that can explain the differences between the results obtained in this study with the others involves the presence of aprismatic enamel on vestibular or lingual surfaces, and absents on cavosurface enamel. The aprismatic enamel creates greater resistance to acid etching, which can interfere in the bond of the self-etching adhesive systems, decreasing their effectiveness. ${ }^{18}$

Despite the lower level of enamel etching associated with the self-etching adhesive primer used in the study, this etching pattern was able to produces bond strength values similar to those obtained with the etch-and-rinse adhesive system. This finding can be attributed to the intra-substrate differences presented by the dental enamel, like presence or absences of aprismatic enamel, or orientation of the prisms. The absence of aprismatic enamel and the prisms in a longitudinal way can favor the bonding of the self-etching systems to the cavosurface region, due to this surface be more susceptible to etching.
When the groups with etch-and-rinse or primer only were compared to the group with both methods, different characteristics of etching was observed. On the cavosurface enamel etched with 35\% phosphoric acid, a demineralization of the central region of the prisms known as type-1 conditioning ${ }^{19}$ was obtained. The self-etching system allowed a slight conditioning, with a withdrawal of the smear layer and negligible increase of the visible roughness. When both etching types were used, one following the other, on the same surface, a demineralization of their peripheral area (Figures $4 \mathrm{a}$ and 4b) apart from the etching of the central region of the prisms occurred. This conditioning type called type $A^{20}$ is considered to be ideal.

Another factor that may have impacted the increase of the bond strength of the double etching group is the primer application. It not only led to an increasing of etching after the phosphoric acid application, but also facilitated the hydrophobic resin infiltration on the etched enamel. Consequently, it increased the mechanical interaction and the bond strength of the adhesive. The effectiveness of the self-etching primer in increasing the bond strength to the surface enamel is related to the fact that most of this etched region consists of the interprismatic region, which presents a deeper etching, increasing the interlocking of the adhesive system.

The self-etch adhesive used in this study is a two-bottle system. After the phosphoric acid etching and primer application, a hydrophobic resin solvent-free is applied at the surface. The better properties of the solvent-free adhesives, 21,22 allied with the etching pattern obtained on the group with the two types of acid etching, can be responsible for the obtained results.

In light of the different etching patterns imposed by the superficial treatments performed in the present study and confirmed by the images in the SEM, the second hypothesis of the study was rejected. It should be noted that it is not the objective of the authors of the present study to compare the results of different studies to show the minimum bond strength of the self-etching system on the enamel, despite previous conditioning, to advocate for the use of this an adhesive in all situations. On the contrary, in cases involving the bonding of the resin-based composites to the vestibular and/or lingual-palatal regions of the teeth, the use of this procedure must be avoided due to the lower bond 
strength of the self-etching systems, even with the previous acid application, to the enamel of these regions. ${ }^{12-16}$ However, on restorations that involve the occlusal and/or proximal regions of the posterior teeth, the self-etching adhesive system can be used, with previous etching of the cavosurface promoting an efficient bond between adhesive system/ substrate.

\section{CONCLUSIONS}

Based on the findings of this study, it can be concluded that:

- In the cavosurface region, the evaluated selfetching system produced bond strength values similar to those obtained with the etch-and-rinse adhesive system.

- When the cavosurface enamel was previously conditioned to the application of the self-etching adhesive system, the results of the bond strength were statistically superior to those observed in the other experimental groups.

\section{REFERENCES}

1. Van Meerbeek B, De Munck J, Yoshida Y, Inoue S, Vargas $M$, Vijay $P$, Van Landuyt $K$, Lambrechts $P$, Vanherle $G$. Buonocore memorial lecture. Adhesion to enamel and dentin: current status and future challenges. Oper Dent 2003;28:215-235.

2. Faria-E-Silva AL, Fabiao MM, Sfalcin RA, de Souza Meneses M, Santos-Filho PC, Soares PV, Martins LR. Bond Strength of One-Step Adhesives under Different Substrate Moisture Conditions. Eur J Dent 2009;3:290-296.

3. Torkabadi S, Nakajima M, Ikeda M, Foxton RM, Tagami J. Influence of Bonded Enamel Margins on Dentin Bonding Stability of One-Step Self-etching Adhesives. J Adhes Dent 2009;11:347-353.

4. Reis A, Moura K, Pellizzaro A, Dal-Bianco K, de Andrade $A M$, Loguercio AD. Durability of enamel bonding using onestep self-etch systems on ground and unground enamel. Oper Dent 2009;34:181-191.

5. Reis AF, Aguiar FH, Pereira PN, Giannini M. Effects of surface texture and etching time on roughness and bond strength to ground enamel. J Contemp Dent Pract 2009;10:17-25.

6. Bradna P, Vrbova R, Dudek M, Roubickova A, Housova D. Comparison of bonding performance of self-etching and etch-and-rinse adhesives on human dentin using reliability analysis. J Adhes Dent 2008;10:423-429.
7. Cavalcanti AN, Mitsui FH, Lima AF, Mathias P, Marchi GM. Evaluation of Dentin Hardness and Bond Strength at Different Walls of Class II Preparations. J Adhes Dent 2009 Sep 30. doi: 10.3290/j.jad.a17524.

8. Pegado RE, do Amaral FL, Florio FM, Basting RT. Effect of different bonding strategies on adhesion to deep and superficial permanent dentin. Eur J Dent 2010;4:110-117.

9. de Oliveira MT, de Freitas PM, de Paula Eduardo C, Ambrosano GM , Giannini M. Influence of Diamond Sono-Abrasion, Air-Abrasion and Er:YAG Laser Irradiation on Bonding of Different Adhesive Systems to Dentin. Eur J Dent 2007;1:158166.

10. Inoue $S$, Vargas MA, Abe $Y$, Yoshida $Y$, Lambrechts $P$, Vanherle G, Sano H, Van Meerbeek B. Microtensile bond strength of eleven contemporary adhesives to enamel. Am J Dent 2003;16:329-334.

11. Ibarra G, Vargas MA, Armstrong SR, Cobbb DS. Microtensile bond strength of self-etching adhesives to ground and unground enamel. J Adhes Dent 2002;4:115-124.

12. Rotta M, Bresciani $P$, Moura SK, Grande RH, Hilgert LA, Baratieri LN, Loguercio AD, Reis A. Effects of phosphoric acid pretreatment and substitution of bonding resin on bonding effectiveness of self-etching systems to enamel. $J$ Adhes Dent 2007;9:537-545.

13. Soares CJ, Castro CG, Santos Filho PC, da Mota AS. Effect of previous treatments on bond strength of two selfetching adhesive systems to dental substrate. J Adhes Dent 2007;9:291-296.

14. Barkmeier WW, Erickson RL, Kimmes NS, Latta MA, Wilwerding TM. Effect of enamel etching time on roughness and bond strength. Oper Dent 2009;34:217-222.

15. Erickson RL, Barkmeier WW, Latta MA. The role of etching in bonding to enamel: A comparison of self-etching and etch-and-rinse adhesive systems. Dent Mater 2009;25:14591467.

16. Torres CR, Barcellos DC, Pucci CR, Lima Gde M, Rodrigues $C M$, Siviero M. Influence of methods of application of selfetching adhesive systems on adhesive bond strength to enamel. J Adhes Dent 2009;11:279-286.

17. Shimada $Y$, Tagami J. Effects of regional enamel and prism orientation on resin bonding. Oper Dent 2003;28:20-27.

18. Whittaker DK. Structural variations in the surface zone of human tooth enamel observed by scanning electron microscopy. Arch Oral Biol 1982;27:383-392.

19. Galil KA, Wright GZ. Acid etching patterns on buccal surfaces of permanent teeth. Pediatr Dent 1979;1:230-234.

20. Hobson RS, Rugg-Gunn AJ, Booth TA. Acid-etch patterns on the buccal surface of human permanent teeth. Arch Oral Biol 2002;47:407-412. 
21. Cadenaro $M$, Breschi L, Rueggeberg FA, Suchko $M$, Grodin E, Agee K, Di Lenarda R, Tay FR, Pashley DH. Effects of residual ethanol on the rate and degree of conversion of five experimental resins. Dent Mater 2009;25:621-628.

22. Malacarne-Zanon J, Pashley DH, Agee KA, Foulger S, Alves MC, Breschi L, Cadenaro M, Garcia FP , Carrilho MR. Effects of ethanol addition on the water sorption/solubility and percent conversion of comonomers in model dental adhesives. Dent Mater 2009;25:1275-1284. 